Transportation Research Forum

Air Travel in Small Communities: An Econometric Framework and Results

Author(s): Dipasis Bhadra

Source: Journal of the Transportation Research Forum, Vol. 43, No. 1 (Spring 2004), pp. 19-37

Published by: Transportation Research Forum

Stable URL: http://www.trforum.org/journal

The Transportation Research Forum, founded in 1958, is an independent, nonprofit organization of transportation professionals who conduct, use, and benefit from research. Its purpose is to provide an impartial meeting ground for carriers, shippers, government officials, consultants, university researchers, suppliers, and others seeking exchange of information and ideas related to both passenger and freight transportation. More information on the Transportation Research Forum can be found on the Web at www.trforum.org. 


\section{Air Travel in Small Communities: An Econometric Framework and Results}

In this paper, we examine the relationship between origin and destination $(O \& D)$ travel and local area characteristics for small communities. By combining data from Bureau of Transportation Statistics/United States Department of Transportation (BTS/DOT) on O\&D travel with that of local area economic and demographic activities supplied by the United States Bureau of Economic Analyses (BEA), Department of Commerce, we specify a semi-log linear demand relationship for $O \& D$ travel in small communities. The resultant dataset covering the period 1999-2000 has more than 4,700 observations; 2,686 for communities without any small hubs, and 2,087 for communities with small hubs. Using a weighted least squares method, we estimate demand for air travel, defined by O\&D pairs, for smaller communities. Our results indicate that average fare affects passenger demand negatively for both types of communities. Our results also confirm that local area income affects travel positively in both cases. However, the levels of travel tend to be affected by population differently; origin population affecting traffic negatively for smaller communities without any hub and positively for communities with small hubs. Presence of smaller hubs affects air travel positively; and market concentration of airlines affects $O \& D$ travel negatively. We demonstrate in this paper that factors affecting the economic framework are the ultimate factors driving the demand for air travel in the small communities in the long run. We also discuss approaches using our methodology for deriving bottom-up projections. These projections have distinct characteristics that may make them more useful for analyzing flow features, such as passenger and aircraft flows by local areas, determining and prioritizing infrastructure investment requirements by local areas, and determining revenue potential from these travels.

\section{by Dipasis Bhadra ${ }^{1}$}

\section{INTRODUCTION}

The technology boom of the 1990s had a significant impact on the economic, demographic, and social landscapes of the country. As the productive base of the economy restructured, both by expansion and restructuring of the existing industries, the physical landscape of the country changed. While some of the traditional manufacturing and service-based state economies lost comparative economic advantages, new growth areas emerged. Thus, while New York, Illinois, and Michigan registered a net migration loss, Colorado, Nevada, Georgia, and Texas registered huge demographic gains in 2002 [see U.S. Bureau of Economic Analysis (BEA (2002)]. Similar population gains had been registered by these states in earlier years (i.e., 1993-1998) of the technology boom before it crashed in 2000.

While earlier empirical discussion focused primarily on the impact of the changes in employment structure on the larger metropolitan areas ${ }^{2}$ and their infrastructure [see, for example, Button, et al. (1999)], not much attention has been given to addressing the needs and requirements of small communities. ${ }^{3}$ Interestingly enough, many of the structural transformations may have affected demographics and physical landscapes of small communities relatively more than the metropolitan areas. However, identifying and separating these effects could 
be difficult because there are overlaps between small communities and metropolitan statistical areas (MSAs). Consequently, it is difficult to discuss planning needs of small communities without reference to the broader MSAs wherever they are applicable.

This paper is an attempt to fill this void. In particular, it is designed to determine and evaluate the transportation needs, aviation needs in particular, of small communities in the United States. While we develop and use an analytical framework for the aviation sector, it can be easily extended to analyze, estimate, and forecast other modes of transportation as well. The paper is organized as follows: Section II briefly reviews the literature and sets out the context; Section III develops an analytical framework to discuss the determinants of aviation transportation needs of small communities; Section IV describes the data, econometric methodology, and results; Section V discusses ways to derive forecasts using this framework; and Section VI concludes by drawing some specific and broad policy conclusions.

\section{BACKGROUND}

Air transportation in this country has a hierarchical structure. Much of the scheduled air transportation passes through the large hubs, ${ }^{4}$ a feature that is consistent with population distribution.

The variation in population concentration in the country is clearly evident from Figure 1.

Table 1: Hubs, Nonhubs, Airports, and Enplanement in 1999

\begin{tabular}{|c|c|c|c|c|c|}
\hline $\begin{array}{c}\text { Hub } \\
\text { Classification }\end{array}$ & $\begin{array}{c}\text { Definition } \\
\text { (\% of Total } \\
\text { Enplaned } \\
\text { Passengers) }\end{array}$ & $\begin{array}{c}\text { Number of } \\
\text { Hubs/ } \\
\text { Nonhubs }\end{array}$ & $\begin{array}{c}\text { Number of } \\
\text { Airports }\end{array}$ & $\begin{array}{c}\text { Passengers } \\
\text { Enplaned }\end{array}$ & Passengers (\%) \\
\hline Large & 1.00 or more & 29 & 69 & $458,665,099$ & 75.11 \\
\hline Medium & $0.25-0.999$ & 31 & 48 & $96,394,866$ & 15.79 \\
\hline Small & 0.05 to 0.249 & 56 & 73 & $38,644,557$ & 6.33 \\
\hline Nonhub & Less than 0.05 & 577 & 604 & $16,924,194$ & 2.77 \\
\hline Totals & & $\mathbf{6 9 3}$ & $\mathbf{7 9 4}$ & $\mathbf{6 1 0 , 6 2 8 , 7 1 6}$ & $\mathbf{1 0 0 . 0 0}$ \\
\hline
\end{tabular}

http://www.bts.gov/publications/airactstats/intro.html

Figure 1: Population in the United States: Census 2000

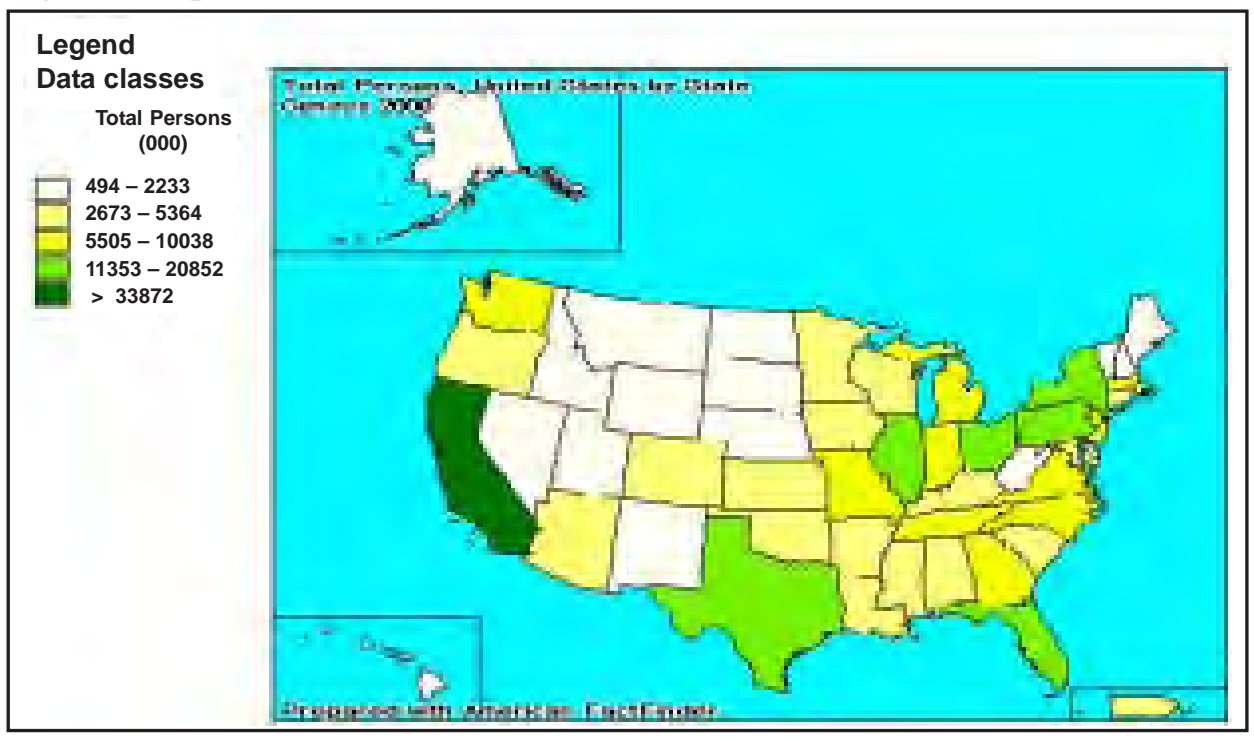

Source: http://factfinder.census.gov/ 
The location and catchment areas of the airports, major airline hubs in particular, tend to correspond fairly well with that of the population centers. However, the locations of airports at small communities appear to be evenly spread throughout the whole country [Figure 2].

Despite this apparent geographic evenness, the size of the market plays a crucial role in determining both the extent and depth of quality of aviation services. As Figure 3 indicates, the frequency of service is dependent on population in the small communities: the larger the number of inhabitants, the greater the number of daily departures. In addition, while turboprops serve all small communities, jet services tend to be available only for rela- tively larger communities within the broad definition of small communities. Similarly, the number of hub and non-stop destinations tend to increase as communities reach relatively higher size.

Given the structure of the economies and relatively lower frequencies, it is likely that smaller communities will be affected disproportionately more by the economic slowdown. Air travel in small communities began to slow down earlier in 2001; the effect was more pronounced after Sept. 11, 2001 (9/11). The change in total daily departures for small communities was about 20\% lower in October 2001 compared with October 2000 [GAO (2002)].

Figure 2: Location and Estimated Catchment Areas of 202 Small Community Airports in the Continental United States

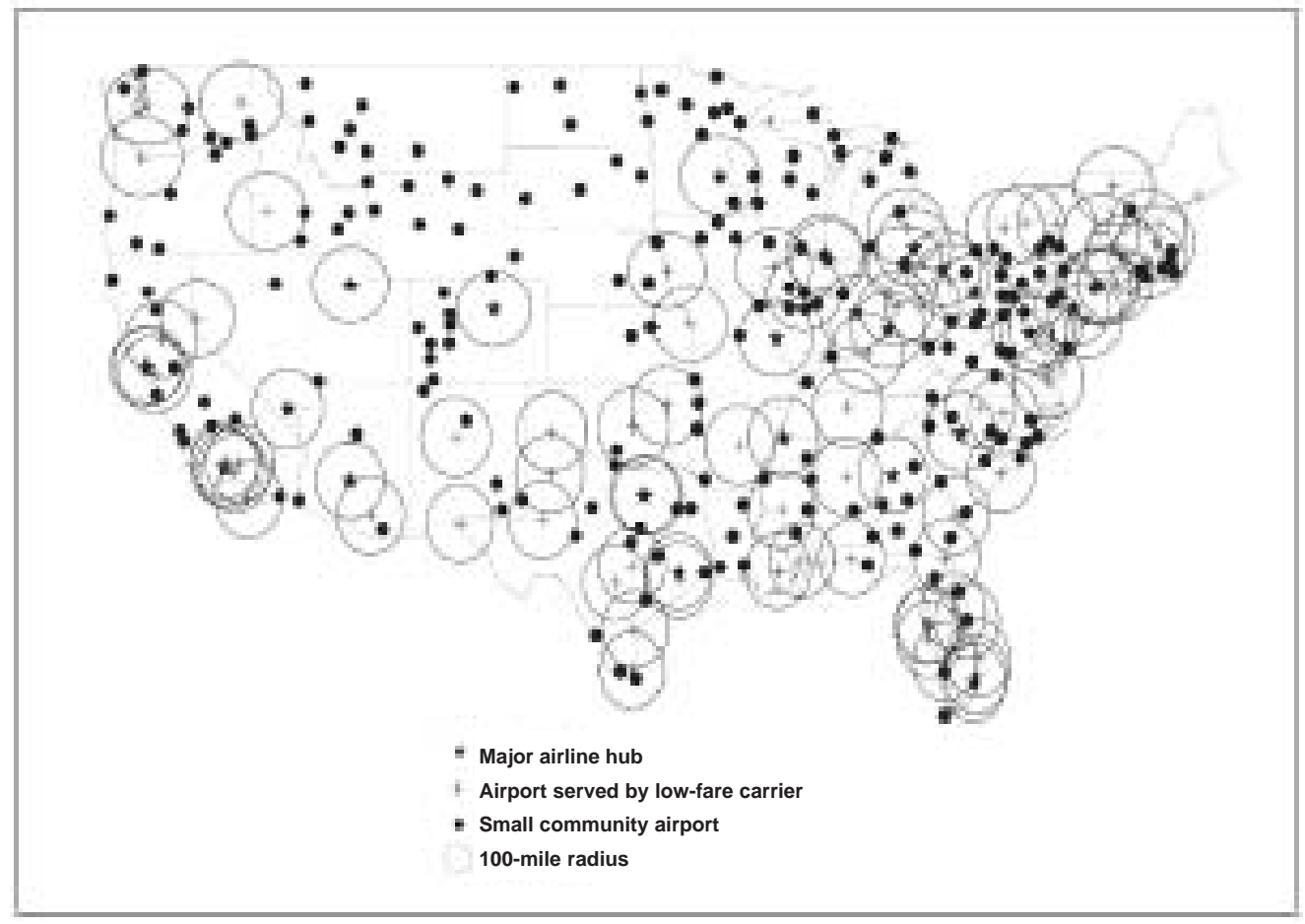

Source: GAO (2002). 
Figure 3: Comparison of Service Indicators Across Small Communities by Population Category, October 2000 (Median Service Levels)

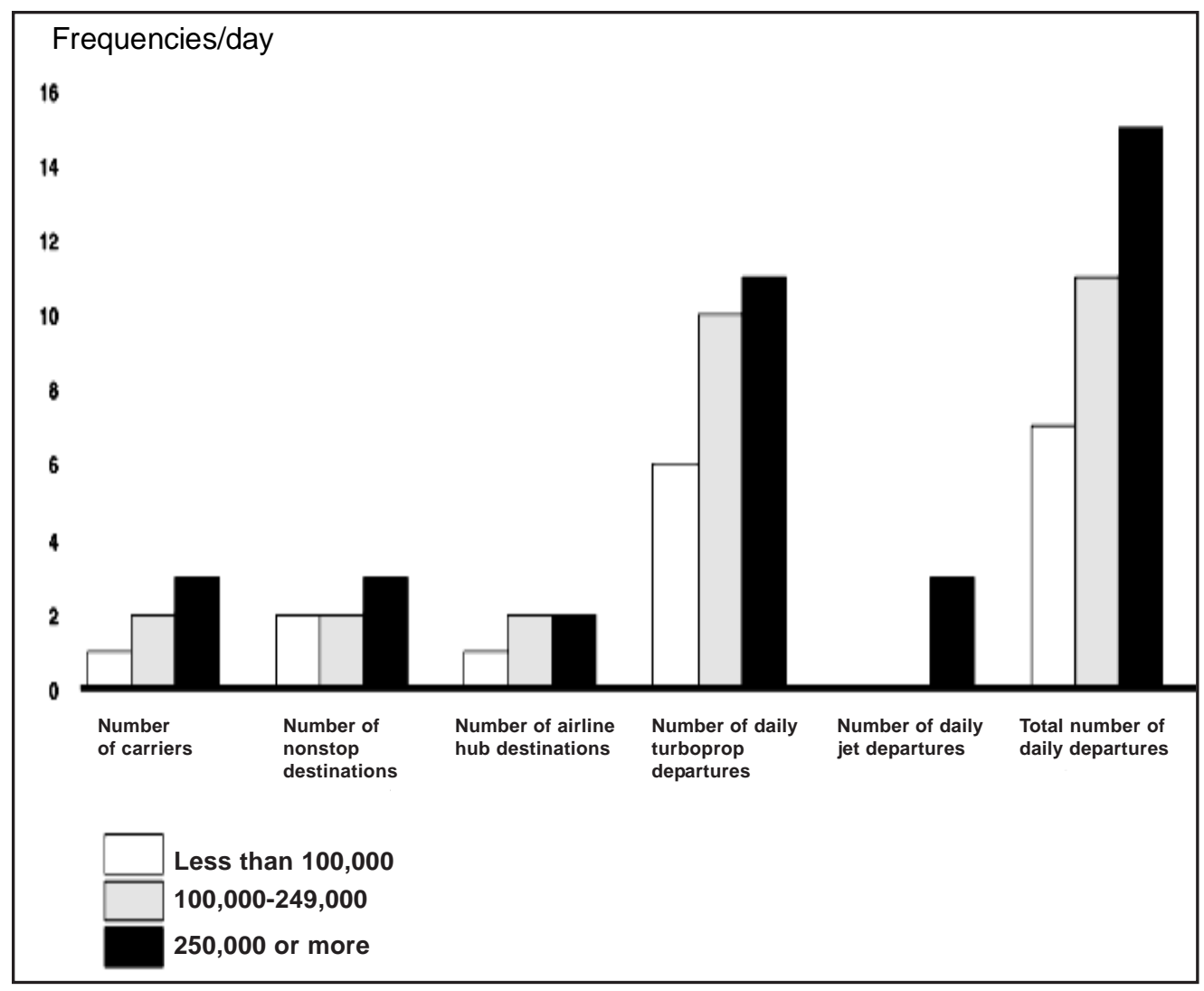

In comparison, the decline in daily scheduled operations in the top 45 Operations Network (OPSNET) airports was slightly over 15\% [Figure 4]. ${ }^{5}$ Total scheduled passenger traffic, on the other hand, declined slightly more than $7 \%$ in 2001 compared to 2000 [see Air Transport Association (2002)].

Despite the overall similarities in declining operations in the nation's largest and smallest airports, the effect was far more disproportionate to the smaller communities because they had very limited services to begin with. Consequently, smaller communities have lost access to numerous destinations through onestop connections of air service as air carriers pulled out of the community [see also GAO
(2002)]. Examining the data, it becomes evident that the frequency of air service and quality of that service are ultimately determined by the underlying economic and financial conditions. Size and composition of these markets make profitable airline operations difficult in many of them. Smaller communities typically generate very little passenger traffic. ${ }^{6}$ Furthermore, business passengers who are willing to pay premium fares are far less numerous in these communities than they would be in relatively larger metropolitan areas. As a direct result of these factors, smaller communities have less air service, both in terms of frequencies and number of choices. 
Figure 4: Scheduled Operations at the Top 45 Airports

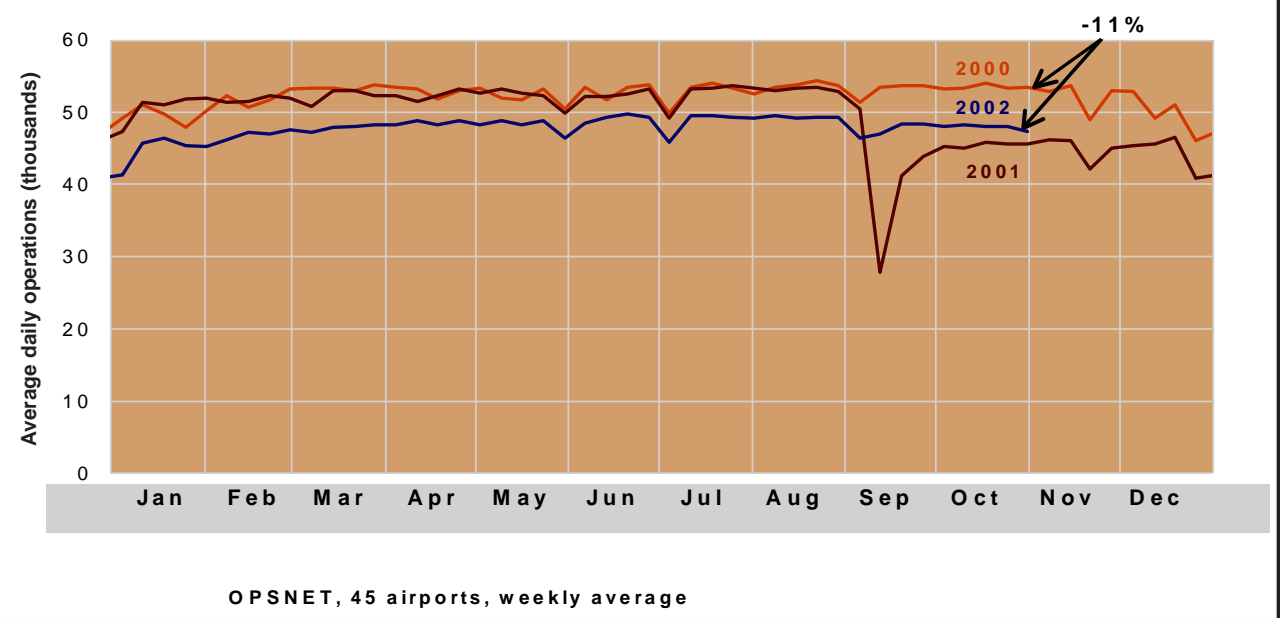

Source: Lamon (2002).

Location choices and scheduling are the reciprocal responses of the commercial air carriers to those underlying conditions. Major and spoke airports that airlines choose to hub and serve depend largely on market demand and cost conditions. Existing empirical research explains this rationale fairly well [see Button et al. (1999), Bhadra and Hechtman (2002)]. In particular, Bhadra and Hechtman (2002) found that optimality, defined in terms of demographics, economic activities, and industry features of the market, is attained when the airport is located within 12 miles of the nearest city. This finding has implications for estimating underlying demand and planning for intermodal transportation infrastructure for communities within the optimal radius of the airport. Cost considerations, on the other hand, drive the hub-and-spoke networks that have formed the basis around which major airlines are organized. Empirical studies on industry structure [e.g., Brueckner and Spiller (1992), Brueckner, Dyer, and Spiller (1992), Rutner and Mundy (1996), and Oster and Strong (2001)] have provided a foundation for many policy prescriptions [USDOT (2001)] that may affect small communities as well.

Thus, it is clear that much is at stake in understanding passenger demand and location choices of air carriers at the local level. Factors governing the industry, combined with factors that are essentially local, are critical for the existence of airlines as a whole. All these point to the fact that local economics play, and will continue to play, significant roles in determining the fate of the emerging airline business models in the future. It appears that choosing the right business model(s) has become the key for survival of the entire airline industry, especially post 9/11 [see Wall Street Journal (June, 2002); Costa et. al. (2002)]. Finally, aircraft manufacturing, to a large extent, is also dependent on the patterns of networks ${ }^{7}$ emerging from the future of the dominant business models [see Economist (April, 2002)]. 


\section{What Determines Passenger Demand of Small Communities?}

It is essential, therefore, that we understand how demand for air travel is determined at the local level. After all, local economies and demographics, together with airline industry characteristics in the market routes, influence the way airlines meet travelers' demand resulting in the route network that we observe in the National Airspace System (NAS) today. Once we understand these relationships it is then hypothesized that these relationships can be used to derive future demand and transportation needs of the small communities.

The empirical literature [for example, Battersby and Oczkowski (2001); GAO (2002)] stipulates that personal income, next to price, is the key factor determining the demand for air travel. It is reasonably certain that personal income, like gross domestic product (GDP), will affect air travel between O\&D pairs positively. Instead of using aggregate GDP for the country, or even for the state as a whole, we propose to use local area personal income. In other words, we hypothesize that local area air travel demand can be best estimated by local area income. Due to this focus on local O\&D demands, we call this approach a bottom-up approach as opposed to a top-down structural approach. Even though this specification alters the way we handle the demand for air travel under a macro-structural model, it builds on the central theoretical premise that local area personal income as opposed to country's GDP determines air travel demand reported in O\&D data.

A clear distinction should be made, however, between the bottom-up approach to modeling travel demand and the standard top-down approach, including that of the Federal Aviation Administration (FAA). ${ }^{8}$ First, under FAA's approach, demand, as represented by revenue passenger miles (RPMs), is determined econometrically by GDP, among other things. This estimated relationship is then allocated from the top down to the terminal areas, taking into consideration the historical shares of the airport, master plans, and expert opinion to derive a terminal area forecast (TAF). Hence, it is a top-down approach. In contrast, our approach is based on econometric relationships that are estimated at the lowest available level (i.e., O\&D travel). While TAF is designed to serve as a terminal area planning tool, our approach is primarily intended to understand market routes, i.e., response of passenger enplanement with respect to a set of explanatory variables. Moreover, this approach can be used to derive $O \& D$ forecasts and forecasts for terminal areas by using the projected values of independent variables at the local level and, hence, can be called a bottom-up approach.

Second, population of local areas plays an important role in determining O\&D traffic. Effects of population may not be as obvious as that of income. For instance, one can expect that as population increases, and the level of economic activities increase, O\&D travel will increase, thus resulting in a positive relationship with demand for air travel. However, as the intensity of economic activities increase, so may the congestion and negative externalities at the local airports. This is particularly true for small communities. Thus, as population in small communities increases, we may also anticipate that air travelers may choose airports outside the geographical boundaries of the community, especially if there are other alternatives available within the catchment areas.

Third, the empirical literature in urban economics postulates that trip distance is "bad" in the sense that it reduces utility by reducing leisure which is "good." Thus, as trip distance increases, it is expected that demand will decline. We may call this a direct effect of distance on passenger demand. ${ }^{9}$ Passenger demand will go down as distance increases under these circumstances [Mills and Hamilton (1993)]. However, this may not be true when air travel is limited to shorter distances. Notice that on shorter trips, travelers have more choices. Thus, in choosing air travel over other modes, a representative traveler makes a conscious decision by comparing the net marginal gain from traveling an extra mile 
by air as compared to an extra mile traveled by other modes. ${ }^{10}$ Utility can be expected to increase and so will passenger demand, with an extra mile traveled by air as long as net returns from air travel exceed that of other modes. We can call this the substitution effect of distance on passenger demand. One may expect to observe, therefore, a positive impact of distance on passenger demand for short-haul trip distances (and thus, stronger substitution effect), with a negative impact otherwise (and thus, the direct effect dominating the substitution effect).

Fourth, the empirical literature cites evidence for [USDOT (2001); Oster and Strong (2001)] and against [GAO (2001)] the stipulation that airlines practice discriminatory pricing based upon market shares. ${ }^{11}$ It is true that having a large market share may facilitate some power over pricing and thus may have some influence over the total passengers served. However, a larger market share by a dominant airline may also imply, especially for smaller communities, that passengers may have limited choice of airlines. This may then deter the air traveler from choosing the local airport, and opt for others within the catchment area. This provides an incentive for airlines to act price competitively even though they may enjoy a monopoly at a small airport.

Finally, congestion and delays have serious consequences on air travel. Financial cost, scheduling complexities, and withdrawal of services leading to lack of competition are some of the consequences of airport delays and en route congestion [see former Administrator Garvey's testimony: http:// www.faa.gov/apa/TESTIMONY/2001/ 315tejg.htm (March, 2001) for more on these issues]. The FAA data show that during the first nine months of 2000, delayed, canceled, or diverted flights affected 119 million passengers. Initial analysis indicates that delays in 2000 cost the airlines an estimated $\$ 6.5$ billion, up from $\$ 5.4$ billion in 1999. [see http:/ /api.hq.faa.gov/APO130/DCOS1995.HTM for more details]. As the former FAA Administrator Jane Garvey pointed out, there are many conditions that cause delays: bad weather, inoperable runways, airport capacity limitations, aircraft equipment problems, airline maintenance and flight crew problems, and air traffic equipment outages [see http://www faa.gov/apa/TESTIMONY/2001/ 315tejg.htm for details]. ${ }^{12}$ Studies show that bad weather is the primary cause for delays (more than 70\%), resulting in severe economic losses [see Jensen, et al. (1999)]. Unpredictable stormy weather takes place during the late spring and summer months. During these periods, weather is often unpredictable, leading to serious enroute and airport delays. In order to mitigate this problem, the FAA initiated a collaborative partnership with the airline industry, known as the spring-summer initiative, that contributed [see, for example, http:// www.faa.gov/programs/oep/printerfriendly/ ER.pdf ] to the FAA's Operational Evolution Plan. ${ }^{13}$ On the other hand, summer is the time when holiday travel takes place in the country, thus creating a positive impact on the overall passenger demand. To take into account the weather effect at particular times of the year and summer's effect on passenger travel, we consider a quarterly proxy, roughly approximating spring and summer weather, as a factor influencing passenger demand for air travel between O\&D pairs.

Based on the above discussion, the passenger demand for small communities, therefore, can be stated as follows:

$$
\begin{aligned}
& \text { (1) } \text { Pax }_{\mathrm{ij}}=\mathrm{F}\left(\mathrm{f}_{\mathrm{ij}} ; \mathrm{PI}_{\mathrm{ij}}, \text { Population }_{\mathrm{ij}},\right. \\
& \text { Distance }_{\mathrm{ij}} \text {, Market Power } \\
& \mathrm{ij}
\end{aligned}
$$

where $\mathrm{i}$ = origin city; $\mathrm{j}$ = destination city; Pax = average daily $\mathrm{O} \& \mathrm{D}$ passengers; $\mathrm{D}=$ dominant airlines; $\mathrm{f}$ = average one-way fare; $\mathrm{PI}=$ personal income; Distance $=$ distance traveled between O\&D markets; Market Power = share (\%) of passenger demand by dominant airlines (D) in total O\&D market; and season = spring and summer season, a dummy variable.

The signs of the variables, following the logic discussed above, can be shown to have an impact on passenger demand in the following fashion: 


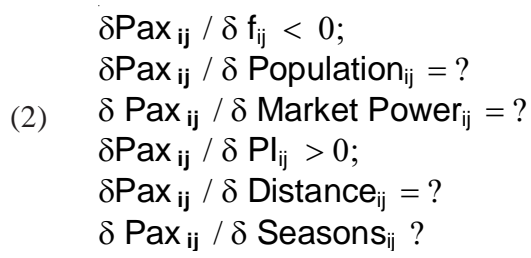

It is clear from the above exposition that beyond standard stipulations, such as on fare and personal income, we do not have clear a priori hypotheses for most of the variables. Therefore, it makes sense to estimate demand for air travel by O\&D markets for small communities and derive useful information, including forecasts, from estimated coefficients.

\section{ECONOMETRIC ESTIMATION: DATA, METHODOLOGY AND RESULTS}

Conceptually speaking, our econometric framework makes use of the same economic logic ${ }^{14}$ presently employed in the top-down framework. ${ }^{15}$ Primary data for this analysis is based on the $10 \%$ O\&D sample obtained from the Bureau of Transportation Statistics (BTS) [see http://ostpxweb.dot.gov/aviation for details]. In addition, we use T-100 schedule data $^{16}$ collected by the BTS. We combine the O\&D data with local economic, demographic and spatial variables collected by the BEA. We use data only for small communities. Using the definition from Table 1, our empirical work thus relates to two types of communities, communities with small hubs and communities without any hubs. In 1999, communities with small hubs had a share of $6.33 \%$ of enplaned passengers, while communities without hubs had $2.77 \%$. Although their shares of enplaned passengers were relatively small, airport infrastructures are primarily located in small communities [see Figure 2]. Therefore, it is essential to understand the determinants of passenger demand in small communities, because this information could become essential in terms of medium- to long-term planning of airport infrastructure. To represent the population of communities with small hubs and no hubs, our dataset contained 2,686 observations for small communities without any hubs and 2,087 observations for communities with small hubs; and thus the combined dataset consists of almost 4,800 observations for eight quarters (first quarter of 1999 to fourth quarter of 2000). ${ }^{17}$

\section{DATA}

Our data come from multiple sources. We combine data on passenger movements by origin and destination areas with local area characteristics (e.g., income, population, and area), and industry characteristics (e.g., fares, market concentration, and presence of competitive airlines such as Southwest). Aviation statistics come from the BTS while the local area data come from the BEA and the Census Bureau. Some other characteristics, e.g., status of hubs and weather influence during spring and summer, have been given special attention as well.

We use Department of Transportation (DOT)-defined hubs based on aviation activities rather than those defined by commercial airlines' activities [see "Airport Activity Statistics of Certificated Air Carriers” report. (http://www.bts.gov/publications/airactstats/ mapsummary.html); see also Table 1]. In order to associate BTS data sets with economic statistics released by the BEA, we used data within commercial geographic information systems (GIS) software.

We combine the above data with that of local area personal income compiled by the BEA (http://www.bea.doc.gov/bea/regional/ reis). Our analysis takes into account MSA population and per capita personal income, grouped by MSA, for 1999 and 2000. By using MSA codes to join the airport information, population, and per capita income, we built a data base that indexes these data sets by airport. Once these data sets were imported into a single spreadsheet, we calculated total enplanements and commercial services by MSAs with or without hubs.

We also placed the airports and their corresponding MSAs into two groups: small hubs and non-hubs [see Table 1]. Non-hubs were 
Air Travel in Small Communities

those that fell below $0.05 \%$ of domestic enplanements and defined in primary and nonprimary airport categories. At present, there are 282 primary and 127 non-primary nonhubs [see http://www.faa.gov/arp/Planning/ hubtype htm]. Unlike the BTS, we applied these definitions to both the hub MSAs and their component airports. Thus, we have data for both MSAs and airports.

The dataset that we use for our analysis and demonstration here is somewhat limited in comparison to the $10 \%$ O\&D sample. ${ }^{18}$ First, the O\&D travel data used in this paper have been extracted from the original Database No. 1A (DB1A). BTS/DOT personnel then combine these data with other market information to obtain the information they report to the public. BTS/DOT does not report the actual airport-to-airport travel (as reported by the $10 \%$ sample); rather, it is reported for the final market as represented by city pairs. This is done to protect market-specific information that airlines report in the $10 \%$ sample. Consequently, for markets in which proportionately more travel takes place (e.g., Atlanta), data tend to be biased in its representation of those markets. Second and most importantly, the dataset used in this paper does not reveal the true itinerary for travelers. As a result, information relating to network travel (i.e., hub-and-spoke travel) is lost. Passengers in the BTS/DOT dataset travel nonstop between O\&D pairs. Although this is likely for smaller distances, hub-and-spoke travel is a fundamental part of today's air travel. ${ }^{19}$ This is clearly a limitation of this study. Third, other information, such as fares that are uniquely associated with an itinerary, is not revealed. In contrast, a calculated average one-way fare, based on the itinerary fares, is reported. While this is a relatively good substitute, it does not allow us to understand the true impact of fares on those itineraries. In order to solve these issues, we conduct a much larger study in our subsequent research where we build and test models, somewhat similar to the one presented in this paper, but based on the more detailed $10 \%$ dataset instead of the one we report here for demonstration purposes.

\section{ECONOMETRIC FRAMEWORK FOR ESTIMATING O\&D PASSENGER TRAFFIC}

We specify the following equation for estimation in semi-logarithmic ${ }^{20}$ form:

$$
\begin{aligned}
\text { In }\left(\text { Pax }_{\mathrm{ij}}\right)= & \alpha+\beta * \ln \left(\mathrm{f}_{\mathrm{ij}}\right)+\chi{ }^{*} \ln \left(\mathrm{PI}_{\mathrm{i}}\right)+\delta \\
& { }^{*} \ln \left(\text { Population }_{\mathrm{i}}\right) \\
+ & \phi^{*} \ln \left(\mathrm{PI}_{\mathrm{j}}\right)+\rho^{*} \ln \left(\text { Population }_{\mathrm{j}}\right) \\
& +\varphi^{*} \ln \left(\text { Distance }_{\mathrm{ij}}\right) \\
+ & \eta{ }^{*} \ln \left(\text { Market }_{\text {Power }^{\mathrm{D}}}\right)+\tau * \\
& (\text { season })+\mathrm{e}_{\mathrm{ij}}
\end{aligned}
$$

where , $\mathrm{i} \neq \mathrm{j}, \mathrm{f}_{\mathrm{ij}}$ is the average one-way fare between $\mathrm{i}$ (origin or $\mathrm{O}$ ) and $\mathrm{j}$ (destination or D); $\mathrm{PI}_{\mathrm{i}, \mathrm{j}}=$ average per capita income at $\mathrm{i}, \mathrm{j}$; Distance $_{\mathrm{ij}}=$ non-stop distance between $\mathrm{i}$ and $\mathrm{j}$; Market Power $^{\mathrm{D}}{ }_{\mathrm{ij}}=$ share of largest carrier (\%) of total passengers between O\&D; and, $\varepsilon_{\mathrm{ij}}$ distributed normally. Parameters attached to the exogenous variables will be estimated from the dataset.

Log-linearity of the demand function implies that the underlying root function is of Cobb-Douglas (C-D) type. This may or may not be true. We make this assumption for two reasons: estimated coefficients of a C-D function have interesting interpretations and can be readily compared with a vast number of other studies for which similar functions have been estimated; and, these functions are computationally less expensive. ${ }^{21}$ In a larger context, however, appropriateness of the functional form itself can be empirically tested.

It is evident that equation (3) resembles a demand function. However, it is well established in the econometrics literature that (3) is part of a simultaneous equation system consisting of both supply and demand functions. Therefore, a straightforward estimation of (3) will produce biased and inconsistent estimates. Generally speaking, an economic system consists of many interdependent variables and relationships among them. In estimating the equations of such systems, econometricians frequently encounter an obstacle known as "the identification problem." It is known to 
be more pronounced when estimating one equation from the system. Fortunately, several techniques (i.e., indirect least squares, two-stage least squares, instrumental variables, three-stage least squares, full information maximum likelihood, and limited information maximum likelihood) have been developed for the estimation of the structural parameters of an a priori specified system of simultaneous stochastic equations. Finally, one of the many assumptions of ordinary least squares stipulates that the variance of the error terms in equation (3) to be constant, i.e., homoskedastic. However, the variance of passenger demand may increase with the variance of, for example, income and population, thus exhibiting heteroskedasticity. Fortunately, there are methods that exist to both test and correct heteroskedasticity in the dataset. ${ }^{22}$

Given our formulation in equation (3), we performed a check for heteroskedasticity using White's linear test for two models, i.e., a model involving no hubs, and a model with small hubs. Using White's test, we found heteroskedasticity in our dataset. Through repeated trial and error, we also found that heteroskedasticitiy tended to be more influ- enced (linearly) by the origin population. Having found this, we employed a standard correction. The standard approach for correcting heteroskedasticity [see Pindyck and Rubenfeld (1991)] requires transformation of the dataset by weighting data to stabilize the variance. Estimation using this approach, called weighted least squares (WLS), is a special case of a more general econometric technique known as generalized least squares.

\section{PASSENGER DEMAND IN SMALL COMMUNITIES AND ITS DETERMINANTS}

We use the Statistical Analysis System (SAS) (v.8) for our estimations. In our estimation, we use the WLS procedures of SAS. We employed the transformed dataset for estimating three models: Model 1 consisting of small communiities without any hubs $(\mathrm{N}=2,686)$; Model 2 consisting of communities with small hubs ( $\mathrm{N}=2,087)$; and Model 3 was estimated using the dataset for both communities combined ( $\mathrm{N}=4,773)$. Results have been summarized in Table 2.

Table 2: Regression Results for Demand for Passengers in Small Communities

\begin{tabular}{|c|c|c|c|}
\hline $\begin{array}{c}\text { Dependent Variable } \\
\text { Log of Average Daily Passengers } \\
\text { Between O\&D pairs }\end{array}$ & \multirow[t]{2}{*}{$\begin{array}{l}\text { Model 1: } \\
\text { Communities } \\
\text { without Hubs }\end{array}$} & \multirow[t]{2}{*}{$\begin{array}{c}\text { Model 2: } \\
\text { Communities } \\
\text { with Small Hubs }\end{array}$} & \multirow{2}{*}{$\begin{array}{c}\text { Model 3: } \\
\text { Both } \\
\text { communities } \\
\text { combined }\end{array}$} \\
\hline Independent Variables & & & \\
\hline Intercept & $-69.6979 *$ & $-3.1158 * *$ & $-6.8343^{*}$ \\
\hline Log of Average Fare & $-0.7596 *$ & $-1.3015^{*}$ & $-1.0721 *$ \\
\hline Log of Origin Per Capita Income & $8.4228 *$ & 0.0357 & $0.8945^{*}$ \\
\hline Log of Origin Population & $-0.7418 *$ & $0.4619 *$ & $0.1614^{*}$ \\
\hline Log of non-stop Distance & $-0.3993 *$ & $-0.1845^{*}$ & $-0.1926 *$ \\
\hline Log of Destination Population & $0.1547 *$ & $0.5810 *$ & $0.3107 *$ \\
\hline $\begin{array}{l}\text { Log of Destination Per } \\
\text { Capita Income }\end{array}$ & $0.5770 *$ & $0.2380^{*}$ & $0.4566^{*}$ \\
\hline $\begin{array}{l}\text { Log of Market Share } \\
\text { of Dominant Carrier }\end{array}$ & $-1.0000 *$ & $-0.6421 *$ & $-0.8481^{*}$ \\
\hline $\begin{array}{l}\text { Seasonal Dummy } \\
(\text { spring \& summer }=1 \text {; else }=0)\end{array}$ & $-0.1040 *$ & 0.0441 & $-0.0500 * * *$ \\
\hline $\begin{array}{l}\text { Hub dummy } \\
(\text { small hub = } 1 \text {; else }=0)\end{array}$ & -- & -- & $0.3178^{*}$ \\
\hline $\operatorname{Adj} \mathrm{R}^{2}$ & 0.1838 & 0.4947 & 0.1909 \\
\hline Model F & 76.62 & 256.37 & 126.21 \\
\hline $\mathrm{N}$ & 2686 & 2087 & 4773 \\
\hline
\end{tabular}

*: 99\%; **: 95\%, and ***: 90\% levels of significance. 
The F statistic suggests that the model specifications are quite good. The adjusted $\mathrm{R}^{2}$, on the other hand, indicates that while Models 1 and 3 do not explain the variation in the dependent variable that well, Model 2 appears to be a relatively better fit. A low adjusted value of $\mathrm{R}^{2}$ is quite common, especially when the time series is relatively short. The GAO (2002) study also reports an $\mathrm{R}^{2}$ of about 0.20. Structural stability of time series data that often ensures high $\mathrm{R}^{2}$ was not present for the eight quarters of data that we used in this study. Due to this shortcoming, forecasts based on the estimated parameters, especially for Models 1 and 3, will be poor.

The average number of daily passengers from the small communities without any hub at the origin location is around 59 passengers, while it is around 47 for communities with small hubs. ${ }^{23}$ Furthermore, there does not seem to be any hub premium; an average passenger pays \$229 in communities without any hub while those with a small hub pay an extra dollar despite the observed variations in airline market shares. The dominant carrier's average market share in communities without any hub (60\%) exceeds those with small hubs (53\%). In other words, market power does not seem to translate, on average, into differences in average fares for this dataset.

Estimated parameters of both the models indicate that results are significant for most of the variables. Comparatively speaking, Model 2 (i.e., communities with small hubs) is a better fit than Model 1 (i.e., communities without any hubs). When we combine the two datasets, the results are more like Model 1 than Model 2 with a couple of differences (i.e., magnitude of log of origin income, and sign of log of origin population). The overall resemblance between the two models with some noted exceptions below indicates that factors that drive air travel in small communities, with or without hubs, are similar. Therefore, some projections of the future may be derived, especially for the Model 2, from these quantitative relationships.
Average Fare. Controlling for other exogenous variables, we find that average one-way fare affects travel demand negatively. This ensures that the underlying demand curve is negatively sloped. The absolute magnitude of the elasticity parameter exceeds 1.0 for communities with small hubs but is less than 1.0 for communities without any hubs; thus suggesting that demand is elastic in the former communities while inelastic in the latter. Our estimated models indicate that for a $1 \%$ increase in fare, passenger demand would decline by $1.3 \%$ for communities with small hubs, and by $0.76 \%$ in communities without any hubs. The elastic demand of Model 3, may be due to the fact that air travel in smaller communities faces competition from other modes of travel, competition from other airports and/ or larger airports, or, relatively few premium fare passengers located in smaller communities. Any one or a combination of these factors may cause the overall demand to be elastic.

Per Capita Income at the Origin Communities. Interestingly, income tends to affect air travel of smaller communities very differently. In small communities without any hubs, demand is highly elastic with respect to income; a 1\% increase in income would induce an $8 \%$ increase in travel. However, demand is (insignificantly) inelastic with respect to income for communities with small hubs. For the sample as a whole (Model 3), a 1\% increase in income would induce only around $0.90 \%$ response in air travel. While the difference in magnitude of the elasticity parameters is somewhat difficult to explain precisely, the implication is clear. A comparison of the size of the elasticity parameters among three models, controlling for all other variables, indicates that air travel in smaller communities with hubs is less responsive to changes in income than those without any hubs. This leads us to believe that air carriers would be inclined to cut services faster in communities without any hubs during an economic slowdown. 
Population of the Origin Communities. Population affects air travel negatively for small communities without any hubs (Model 1), positively for communities that have small hubs (Model 2), and positively for all communities (Model 3). Generally speaking, an increase in population is expected to increase travel demand. But our results indicate that for a $1 \%$ increase in origin population, air travel would actually decline by a $0.74 \%$ for small communities without any hubs. In comparison, air travel would increase by $0.46 \%$ in communities with small hubs. For all communities combined (Model 3), a 1\% increase in origin population would increase air travel by $0.16 \%$.

These results have some interesting implications. First, an increase in population may not necessarily translate into actual air travel due to schedule constraints of smaller airports. More importantly, substitutability may occur where airports with smaller (or medium and larger, for that matter) hubs begin to compete with smaller airports without hubs in the area. In other words, airports within the catchment area, both small and large, become available for air travel with expanding population in small communities. ${ }^{24}$ Some substitutability of airports and airlines may then become the driving force ${ }^{25}$ making it more of demand for the entire metro areas than small communities, per se.

Non-stop Distance. Travel demand is inversely related to non-stop distance for all three models. However, the decrease in demand is twice as large for communities with small hubs than those without hubs. In particular, for each $1 \%$ increase in non-stop trip distance miles between O\&D, demand is reduced by $0.40 \%$ for communities without any hubs (Model 1), 0.18\% in communities with small hubs (Model 2) and 0.19\% for all communities combined (Model 3). Both the magnitude and significance of the estimated parameters indicate that there may be some upper bound on the trip length of the point-topoint market, especially for airlines serving small communities.
Population at the Destination Communities. Unlike the mixed effect of population of origin communities, population at destination communities affects air travel positively for all our models. The population elasticity, ceteris paribus, indicates that for a $1 \%$ increase in population of the destination communities, the increase in air travel between O\&D pairs has a range of $0.15 \%$ (Model 1 ) to $0.58 \%$ (Model 2). The statistical significance of this variable implies that destination population is important for travel from small communities.

Per Capita Income of the Destination Communities. Income of the destination communities affects $O \& D$ travel positively; however, demand is inelastic for all three models. The result for the first model is especially interesting in comparison to that of income from origin communities; for, as we noted earlier, travel demand is highly elastic with respect to income of origin communities.

Market Share of Dominant Carrier at the Origin Communities. Market share (\%) of the dominant carrier affects travel demand negatively in all three models. A higher market share of an airline is equivalent to relatively fewer choices, ceteris paribus. A larger market share, on the other hand, may also be necessary for overall market viability. However, the estimated negative parameters indicate that air travelers tend to choose other modes (i.e., mode substitution), or other airports (i.e., airport substitution) within the catchment areas as the market concentration of the major airline increases.

Seasonal Dummy. As noted earlier, seasonal dummies have been used to represent spring/ summer and other seasons, respectively. Interestingly enough, people from small communities, especially those without small hubs (Model 1) and communities as a whole (Model 3 ), are likely to travel less in spring and summer from their own airports. This may happen for several reasons. First, it is possible that schedules are restrictive for smaller airports during these months due to airlines' ef- 
forts to serve relatively profitable markets more. Second, and more likely, these months are also proxies for bad weather affecting smaller airports far more disproportionately than the larger ones. ${ }^{26}$ A negative impact may, therefore, simply capture the underlying effect of weather on air travel.

Hub Dummy. Model 3 uses a dummy to represent communities with smaller hubs, i.e., 0 = no hub; and 1 = small hubs. We model this to capture any structural difference between the two datasets arising from this difference in definition alone, holding everything else constant. The result indicates that hubbing has a positive impact on air travel compared to no hubbing. More schedule choices, greater competition, and bigger market size may lead to higher levels of demand for air travel from small communities with hubs. This has also justified our segmenting the data into two separate datasets, i.e., communities without small hubs (Model 1) and communities with small hubs (Model 2). ${ }^{27}$ Model 2 is a relatively better fit to the data than Models 1 and 3 .

\section{FROM ESTIMATED AVIATION PASSENGER DEMAND TO ANALYZING THE AVIATION NEEDS OF SMALL COMMUNI- TIES IN THE FUTURE}

The estimated equations from the above three models can be used to derive O\&D passenger demand, corresponding to forecasted ${ }^{28}$ or expected changes in exogenous variables. ${ }^{29}$ Using these values, we can then derive the aviation infrastructure needs of small communities in the future. Finally, using the projections of O\&D aviation passengers, we can calculate the economic and social benefits arising at the origin and destination communities.
There are some variables for which forecasted values are readily available, e.g., personal income and population. For others, such as distance, one can make assumptions based on industry trends, possible O\&D markets, and available technologies. But for others, forecasts are not available. In particular, future fare information is not available; neither are available future values for market shares and the effect of low-fare carriers, for example. The unavailability of this information poses limitations on making passenger projections by O\&D market. However, it is also possible to derive a range of scenarios based on assumed values for the variables ${ }^{30}$ for which forecasts are not available. Such policy simulations may allow us to measure forecast scenarios based on the underlying industry assumptions, the model estimates, and forecasts for other exogenous variables.

Figure 5 shows the expected growth rates of personal income for the 2001-2006 period. In particular, impressive annual personal income growth exceeding $6 \%$ is likely to take place in communities and states of the South Atlantic region followed by impressive gains of $5.6 \%$ and $5.8 \%$ in the Mountain and Middle Atlantic states, respectively. Similar forecasts exist for state population as well. Using our estimated model, we can transform these projected growth rates for population, income, and other exogenous variables into average annual growth rates of aviation demand for small communities in the near future (i.e., 2001-2006), holding everything else constant. Furthermore, using these numbers, we can calculate the total value, both direct and indirect, of aviation demand and its contributions to both origin and destination local economies. This information may prove to be very useful for transportation infrastructure planners, both at the local and state levels. 
Figure 5: Personal Income Average Annual Growth Rate, 2001-06

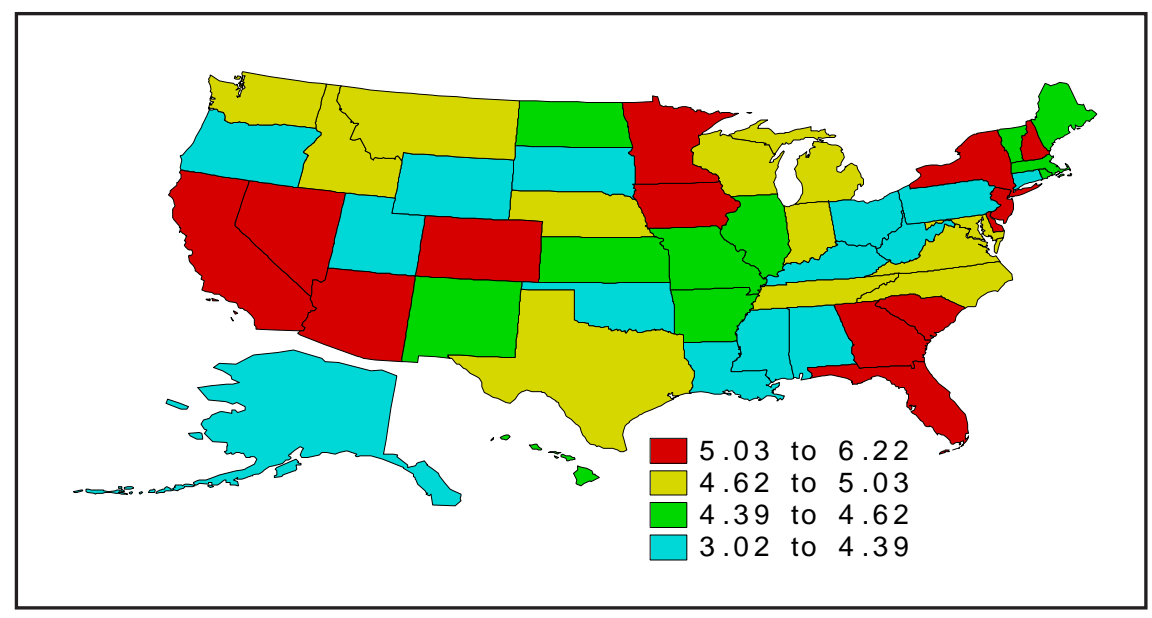

Source: DRI-WEFA, 2002

\section{Conclusions and the Work Ahead}

This paper demonstrates that micro level estimation of transportation demand, aviation in this particular case, can be a powerful tool for local and state level infrastructure planning. In particular, it appears that slight modifications of econometric estimation and use of micro data can result in substantial insights into O\&D travel. For example, it is possible, as the present paper demonstrates, to determine city-pair travel demand and forecasts of the demand by using local area information. Both estimation and forecasts of O\&D travel make use of the local area information, and hence, this methodology should be called a bottom-up approach, distinct from the traditional top-down approaches.

Results from this econometric estimation provide some detailed insights into O\&D travel as well. We are now able to distinguish travel demand between different smaller communities markets. As our results indicate, air travel from smaller communities without hubs is structurally different than those with small hubs. Second, fare elasticities show that air travel from these markets is relatively elastic for communities with small hubs and inelastic for communities without hubs. Third, our results also indicate that market dominance by major airlines has a negative impact on number of passengers between O\&D pairs, perhaps representing the effects of lack of choice more than anything else. Finally, spring and summer tends to reduce air travel in smaller communities, especially in places without hubs.

These are interesting results. However, our study is somewhat restricted by the data. Thus, any policy discussion should await results from our larger work. Nonetheless, this paper demonstrates that much can be learned from studying O\&D traffic. Furthermore, the paper demonstrates that it is possible, and perhaps desirable, to devise O\&D-based market traffic forecasts. While the TAF will continue to play an important role in longer-range planning, our methodology could be used for studies that relate to the network flow aspects of the NAS. 


\section{Endnotes}

1. An earlier version of this paper was presented at the 82nd Transportation Research Board (TRB) annual meeting (Session \# 291) Jan. 12-16, 2003, Washington, DC. Author is a lead economist at The MITRE Corporation's Center for Advanced Aviation System Development (CAASD). The author would like to thank four anonymous referees of the TRB, two anonymous referees and the Editor of this Journal whose suggestions and comments greatly improved the paper. The author would also like to thank participants at session \#291, and colleagues at CAASD's Department of Air Transportation Performance and Policy Analysis for their helpful comments and suggestions during the course of this research and several presentations. Views expressed in this paper including all remaining errors are attributable to the author only. Correspondences can be made to: dbhadra@mitre.org.

2. The Office of Management and Budget (OMB) defines metropolitan areas (MAs), including metropolitan statistical areas (MSAs), consolidated metropolitan statistical areas (CMSAs), and primary metropolitan statistical areas (PMSAs). An MSA is a county or group of contiguous counties that contains at least one city with a population of 50,000 or more or includes a Census Bureau-defined urbanized area of at least 50,000 with a metropolitan population of at least 100,000. In addition to the county containing the main city or urbanized area, an MSA may contain other counties that are metropolitan in character and are economically and socially integrated with the central counties. In New England, cities and towns, rather than counties, are used to define MSAs and called New England Consolidated Metropolitan Area (NECMA). At present, the country has 248 MSAs, and 11 NECMAs. Together, they account for about $78 \%$ of total population. For current MSA information, see http://www.census.gov/population/www/ estimates/metrodef.html

3. Small communities have been defined, for the purpose of this paper, to be those with a population base of 250,000 or less. Census defines small communities as those with population of 50,000 or less while medium communities are those with a population base between 50,000-250,000.

4. Airport hubs are defined in two ways. One is in terms of total enplanement, as defined by the Department of Transportation/Federal Aviation Administration (DOT-FAA) [see Table 1]. Under this definition, broader geographical areas (e.g., metropolitan areas), as opposed to a particular airport, where airports together account for an arbitrary number of enplanement are defined as hubs. The second definition categorizes an airport where a major commercial air carrier has more than one passenger bank structure as a hub. Under this definition, an airport is defined as a hub where inbound flights are scheduled to arrive from multiple origins within a short span of time thus creating a bank of passengers. The coordinated arrival and departure banks together form a wave. Formed efficiently, hubs act as switching centers, intermediating flows between multiple origins and multiple destinations as well as contributing origin and destination traffic of their own [for a discussion, see Bhadra and Hechtman (2002)].

5. Thirty-one of these airports are presently classified as large hub airports.

6. A general rule of thumb in the industry is that it takes about 75 passengers a day to run a profitable airline route. This may vary, depending upon the composition (i.e. business versus leisure) of passengers. Unfortunately, however, almost $1 / 3$ of the scheduled air markets have 10 passengers or less a day [see Bhadra and Wells (2003)]. Serving these markets, therefore, would require taking other factors into consideration, e.g., maintaining a strong hub-and-spoke network that simultaneously minimizes costs and provides a competitive edge, operational reasons including maintenance stops, availability of subsidies programs such as Essential Air Service Programs, political considerations - all eventually leading to pursuit of network-wide profitability as opposed to single-route profitability. Carriers which use smaller communities as feeders to their operational hubs, generally speaking, are also called network carriers.

7. The steady rise of Southwest Airlines in the second half of the 1990s and its apparent reliance on spoke-to-spoke networks have led many to suggest that the future of the air transportation network may very well be a diffused one compared to the current hub-and-spoke network that dominates US air travel.

8. For a discussion on these methodologies, see TRB (2002). 
9. The evidence on rising quality of services, including more leg space and complete sleep travel for business class passengers in particular, offered by many airlines, tend to suggest that there may be a negative relationship between air travel and utility, especially for longer trips.

10. This process will take into account marginal utility from different travel options and their prices.

11. It is unlikely that airlines in small communities could practice perfect price discrimination without jeopardizing their market shares. A second-order price discrimination, where airlines charge only two prices - one for leisure passengers and the other for business passengers - may also be unappealing to airlines for various reasons. Thus, a combination of practices is likely; where airlines would constantly revise their pricing-scheduling options depending upon types of passengers, time of travel, presence of other factors including other airlines, direct vs. transfer travel, availability of other modes, and/or other airports. Hence, price discrimination will be balanced against built-in structural factors that limit the extent of price discrimination.

12. There is a bill (\#H.R. 1407) entitled The Airline Delay Reduction Act pending whereby the House Subcommittee on Aviation was to review requests for provision of antitrust immunity for the airlines to allow them to discuss ways to reduce delays and to consider other possible solutions to the airline delay problem. In order to address these issues, the Committee held a hearing on April 26, 2001 [see http:// www house.gov/transportation/aviation/04-26-01/04-26-01memo html for details].

13. The Operational Evolution Plan (OEP) represents the FAA's commitment to meet the air transportation needs of the United States for the next 10 years by increasing capacity and decreasing delays, while continuing to improve safety and security. The OEP started as a business planning activity that accelerated during the summer delays and cancellations of August 2000, primarily due to dramatic increases in the number of people flying coupled with particularly bad weather that summer. In order to counter these problems in the future, the FAA executives began meeting in late 2000 to discuss a broader strategy to address capacity issues and to continue to get input from the aviation community. To enhance a coordinated strategy, the OEP Executive Team met with representatives from the entire aviation community, including airlines, airports, manufacturers, service providers, pilots, controllers and passengers. The OEP Executive Team agreed to address four problem areas: arrival/departure rates; en route congestion; airport weather conditions; en route severe weather [for more details, see http://www faa.gov/programs/ oep/index.htm].

14. That is, the passenger demand, as represented by revenue passenger miles (RPM), is a function of income as represented by GDP of the country.

15. All available approaches, based on our research and knowledge, reveal that both the industry and FAA employ some variant of the top-down approach. This perhaps makes sense for the industry, given the typical short-term considerations and lack of resources. However, from a medium- and long-term planning perspective, trend projections often arising from top-down approaches may not be an effective tool. More detailed approaches, such as examining the characteristics of O\&D travel may become necessary for situations where aggregate results may be misleading.

16. T100 Segment is the Data Bank 28DS of Form 41 which provides traffic and capacity data of U.S. air carriers. The data are reported by U.S. air carriers operating non-stop between airports located within the boundaries of the United States and its territories [see USDOT(1999) for more details].

17. Choice of eight quarters is purely arbitrary for this demonstration. This dataset is somewhat restrictive because DOT/BTS guards some information to protect airlines' proprietory interests. At the time we were putting this dataset together, data for three years (1998-2000) was available. We decided to drop 1998 because O\&D travel was mistakenly identified by airport-pairs, and not city-pairs as reported in later years. Furthermore, we wanted to create a representative sample for this time-series pooled crosssection dataset without getting into serious computational difficulties for our limited purpose. 
18. The $10 \%$ sample is also much larger. For example, the sample has more than 4.5 million records (i.e., $10 \%$ of more than 450 million total scheduled domestic O\&D passengers) for the year 2000 .

19. A quick calculation suggests that, on average, $25-30 \%$ of passengers use hubs to reach their destinations.

20. It is semi-logarithmic because of our use of the seasonal dummy. The seasonal dummy is specified for binary values of 0 and 1 . Given that $\log$ of 1 is zero and $\log$ of 0 is undefined, we use the binary values as independent variables. We also use a similar dummy to represent hubbing in an expanded version of the model discussed later in the paper.

21. Initial estimations with the larger $10 \%$ sample indicate that the larger the datasets, the longer it takes to run estimations. Some of these costs may be avoided if better communications can be developed between object database connections (ODBC) and SAS.

22.I thank an anonymous referee of this paper for bringing this issue to my attention. Although variance of the economic variables tends to be constant over time, it is a good empirical practice, as we found in this study, to perform a test of heteroskedasticity while pooling both time series and cross-section data and undertake appropriate corrections.

23. A quick comparison with other data (see endnote 5) reveals that small communities in our dataset are representatives of the upper end of the market.

24. Notice here that increasing population leads to, in most cases, spatial expansion as well (i.e., suburbanization of metropolitan areas). Hence, the smaller airports that were not accessible before suburbanization may become accessible. Suburbanization has made access to smaller secondary airports cost effective, and hence economically viable, in many cases (e.g., Manchester Airport in Rhode Island is an example of many such developments).

25. For larger metropolitan areas, Pels, Jijkamp, and Rietveld (2000), show that this substitutability is possible. Replacing metropolitan areas with catchment areas would involve some more spatial complications to their model, but may not fundamentally change the structure or results.

26. Many small communities, generally speaking, are not equipped to handle bad weather (e.g., storm, icing on the runways, etc.) efficiently. Therefore, they are likely to be dropped faster from scheduled service if bad weather develops.

27. I thank the general editor of this journal for leading me in this direction from my earlier classification. Results are improved particularly for Model 2.

28. Due to a relatively poor fit of our models, particularly Models 1 and 3, we do not recommend this with the current models. Ideally, a structural econometric model should be estimated over a long period of time. If the underlying economic logic is reasonable, which appears to be the case from all our estimated models, estimation with a longer data series may produce a better fit.

29. This critically depends on the extent of our ability to forecast the exogenous variables. There are many companies that routinely provide forecasts of many of the exogenous variables, personal income and demographics in particular. After BEA stopped forecasting economic variables a few years ago, industry forecasters depended on these companies for local area forecasts.

30. This process parallels what is known as policy simulations. For example, it is clear that (assumed) declining fares in the future would be representative of stronger industry competitiveness. Similarly, an increase in market share by the majors and/or a decline of shares by minors would reduce competition. Assuming those scenarios (i.e., competitive outcomes emanating from different sources), we would be able to derive scenarios of passenger demand for the future. 


\section{References}

Air Transport Association. See http://www.airlines.org/public/home/default1.asp, (2002).

Battersby, B. and E. Oczkowski. “An Econometric Analysis of the Demand for Domestic Air Travel in Australia.” International Journal of Transport Economics, 28 (2), (2001): 193-204.

Bhadra, D. and D. Hechtman. Determinants of Airport Hubbing in the United States: An Econometric Framework, Public Works Management and Policy (forthcoming), Spring 2004.

Bhadra, D. "Demand for Air Travel in the United States: Bottom-Up Econometric Estimation,” Journal of Air Transportation, 8 (2), 2003, pp. 19-56.

Bhadra, D. and M. T. Wells. "Air Travel in the United States: Determinants and Contributions to Regional Economic Growth,” working paper, The MITRE Corporation, 2003.

Brueckner, J.K., N. J. Dyer, and P. T. Spiller. "Fare Determination in Airline Hub-and-Spoke Networks.” Rand Journal of Economics, 23(3), (1992): 309-33.

Brueckner, J. K. and P. T. Spiller. "Economies of Traffic Density in the Deregulated Airline Industry.” Journal of Law and Economics, 37(2), (1994): 379-415.

Button, K., S. Lall, R. Stough, and M. Trice. "High Technology Employment and Hub Airports.” Journal of Air Transport Management, 5, (1999): 53-59.

Costa, P. R, D. S. Harned, and J. L. Lundquist. “Rethinking the Aviation Industry.” McKinsley Quarterly 2, Risk and resilience section, 2002.

DRI-WEFA. “The Regional Recovery: Where and When.” Audio Conference, June 18, 2002.

Economist. "Boeing vs. Airbus: Towards the Wild Blue Yonder,” April 25th. Business Special section, 2002.

Federal Aviation Administration. FAA Aerospace Forecasts: Fiscal Years 2002-2013. Washington, DC: U.S. Department of Transportation, 2002.

General Accounting Office. Commercial Aviation: Air Service Trends at Small Communities Since October 2000, Report to Congressional Requesters, GAO Report No. GAO-02-432, Washington, D.C., 2002.

General Accounting Office. Aviation Competition: Restricting Airlines Ticketing Rules Unlikely to Help Consumers, Report to Congressional Committees, GAO Report No. GAO-01-831, Washington, DC., 2001.

Jensen, A.J., W. Kuhn, Z. Shavell, E. J. Spear, N. Taber, and M. White. "Economic Effects of Severe Disruptions on Airlines,” MP 99W0000164, McLean, VA: The MITRE Corporation, 1999.

Lamon, K. “Analysis of NAS Performance at OPSNET Airports,” Monthly Briefing, McLean, VA: The MITRE Corporation, 2002.

Mills, E.S. and B. Hamilton. Urban Economics, 5th Edition. New York: Harper Collins College Publishers, 1993.

Oster, C. V. Jr. and J. S. Strong. “Predatory Practices in the U.S. Airline Industry,” Special Report to the USDOT, 2001, http://ostpxweb.dot.gov/aviation/domestic-competition/predpractices.pdf. 
Pels, E., P. Nijkamp, and P. Rietveld. “Airport and Airline Competition for Passengers Departing from a Large Metropolitan Area.” Journal of Urban Economics, 48(1), (2000): 29-45.

Pindyck, R.S. and D. L. Rubinfeld. Econometric Models and Economic Forecasts, 3rd Edition. New York: McGraw-Hill, Inc, 1991.

Rutner S.M. and R. A. Mundy. "Hubs versus Hub-Nots: A Comparison of Various U.S. Airports.” Journal of Air Transportation World Wide, 1(1), (1996): 81-90.

Transportation Research Board. Aviation Demand Forecasting: A Survey of Methodologies, E-Circular No. E-C040, Washington, DC: National Research Council, 2002.

U.S. Bureau of Economic Analysis. Regional Accounts Data, 2002 See http://www.bea.gov/bea/ regional/.

U.S. Department of Transportation. “Airline Customer Service Commitment,” Report No. AV-2001020, Washington, D.C: Inspector General’s Office, 2001.

U.S. Department of Transportation. "Form 41: T-100 Domestic Segment Data of U.S. Air Carriers (Databases 28DS),” Office of Airline Information, 1999.

Wall Street Journal. "Executive Flight: The Age of 'Wal-Mart' Airlines Crunches the Biggest Carriers,” June 18, (2002): A.1.

Dipasis Bhadra is a lead economist at the Center for Advanced Aviation System Development (CAASD) of the MITRE Corporation. Working on issues directly pertinent to national and international aviation, Dipasis' expertise includes cost-benefit analysis, econometric estimation, qualitative choice modeling, time series analysis and forecasting, and program monitoring and evaluation. Dipasis earned his Ph.D. in quantitative economics from the University of Connecticut in 1991. 